\title{
DISPERSAL ABILITIES OF SEVEN SPARSE AND COMMON GRASSES FROM A MISSOURI PRAIRIE ${ }^{1}$
}

\author{
Deborah Rabinowitz and Jody K. RaPP \\ Division of Biological Sciences, University of Michigan, Ann Arbor, Michigan 48109; Division of Biological Sciences, \\ University of Missouri, Columbia, Missouri 65211
}

\begin{abstract}
A B S T R A C T
Seven grass species on an abundance continuum from common to sparse on a Missouri tallgrass prairie were examined for two diaspore traits (morphology and weight), for three dispersal traits (terminal velocity, and mean and maximum lateral movement propagules released in still air from a height of $1 \mathrm{~m}$ ), and for two parental traits (culm biomass at maturity and culm height at dispersal). Dispersal ability, measured in the laboratory as the lateral movement of propagules in the upper $5 \%$ (right tail) of the distribution of distances, is inversely correlated $\left(r_{s}=-0.94\right)$ with biomass abundance. Under constant conditions, seeds of sparse species travel farther than seeds of common species. Dispersal ability is more closely related to a populational attribute (abundance) than to a more proximate characteristic (diaspore weight). Diaspore weight is closely related $\left(r_{\mathrm{s}}=0.97\right)$ to culm biomass of the parent, in apparently simple allometry, and more weakly related $\left(r_{\mathrm{s}}=0.71\right)$ to biomass abundance. Large parents make large seeds. The sparsest species, which is small in stature, has light $(0.08$ to $0.19 \mathrm{mg})$, flattened diaspores with low terminal velocities ( 82 to $87 \mathrm{~cm} \mathrm{sec}^{-1}$ ) and achieves lateral movement (up to $460 \mathrm{~mm}$ ) by tumbling and gliding. Species of intermediate abundance have intermediate stature and diaspore weight ( 1.0 to $1.8 \mathrm{mg}$ ), unornamented propagules, high terminal velocities (191 to $209 \mathrm{~cm} \mathrm{sec}^{-1}$ ) and intermediate dispersal ability (up to $388 \mathrm{~mm}$ ). The three most common species have heavy propagules ( 2.2 to $2.8 \mathrm{mg}$ ), ornamented with long hairs. Although the ornamentation slows fall (96 to $194 \mathrm{~cm} \mathrm{sec}^{-1}$ ), it acts as a "guide parachute," orienting the propagule so that it falls nearly straight downward. The common species, which morphologically appear adapted to longer dispersal, achieve little lateral movement (up to $235 \mathrm{~mm}$ ) under laboratory conditions. Terminal velocity is a misleading descriptor of dispersal because diaspores with similar terminal velocities have differing movement patterns. When diaspores of two species (one tall common species and one short sparse species) are released in still air from their natural height, differences in maximum fall distance observed under constant height of release are lost. When dispersal is observed in the field by means of sticky seed traps, the slopes of the dispersal curves (regression coefficient of In-transformed number of seeds caught on distance from the clump) do not differ from common and sparse species, despite the fact that seeds of the common species are released from greater heights. The orderly differences in dispersal behavior among species due to subtleties of morphology observed under laboratory conditions are masked in nature.
\end{abstract}

SEED DISPERSAL of higher plants has been studied extensively on an observational (Guppy, 1906, 1917; Ridley, 1930; van der Pijl, 1972) or species-by-species quantitative basis (Poole and Cairns, 1940; Salisbury, 1942, 1961; Bakker, 1960; Rabinowitz and Rapp, 1979; Fried-

\footnotetext{
${ }^{1}$ Received for publication 23 April 1980; revision accepted 14 August 1980.

We thank Victoria L. Sork and Gary S. Reese for assistance with the data analysis. Donald R. Strong, Jr., Beverly J. Rathcke, Robert Whelan, William J. Platt, Steven Handel and an anonymous reviewer made helpful comments on the manuscript. This research was carried out while one of us (DR) was a visiting assistant professor at the University of Missouri and a NATO postdoctoral fellow at the University College of North Wales. The work was supported by a Rackham Faculty Research Grant from the University of Michigan and a grant from the NSF (DEB78 11179).
}

man and Stein, 1980; others reviewed in Harper, 1977). We have undertaken a comparative laboratory investigation of dispersal properties in several sympatric related species, supplemented with field observations. While laboratory data on dispersal are by no means a substitute for field data, observations of diaspore movements under controlled conditions reveal distinctions in dispersal behavior among species that otherwise are masked (Sheldon and Burrows, 1973; Burrows, 1973, 1975a, 1975b; Rabinowitz, 1978b, 1978c; Peart, 1979).

The major goal in this study was to see whether four sparse (locally rare) grasses had different dispersal behaviors from three common grasses of the same habitat. Each species was examined for numerous dispersal characteristics: morphology, terminal velocity, 
TABLE 1. Abundance and diaspore weight for seven species of prairie grasses. Taxonomy follows Kucera (1961)

\begin{tabular}{|c|c|c|c|}
\hline Species & Tribe & $\begin{array}{c}\text { Abundance } \\
\left(\mathrm{g} / \mathrm{m}^{2}\right) \\
\bar{x} \pm \text { S.E. }\end{array}$ & $\begin{array}{c}\text { Diaspore weight } \\
(\mathrm{mg}, N=50) \\
\bar{x} \pm \text { S.E. }\end{array}$ \\
\hline $\begin{array}{l}\text { Andropogon scoparius Michx. } \\
\text { A. gerardi Vitman } \\
\text { Sorghastrum nutans (L.) Nash } \\
\text { Festuca paradoxa Desv. } \\
\text { Agrostis hiemalis (Walt.) B.S.P. } \\
\text { Setaria geniculata (Lam.) Beauv. } \\
\text { Sphenopholis obtusata (Michx.) Scribn. } \\
\quad \text { with glumes } \\
\quad \text { without glumes }\end{array}$ & $\begin{array}{l}\text { Andropogoneae } \\
\text { Andropogoneae } \\
\text { Andropogoneae } \\
\text { Festuceae } \\
\text { Aveneae } \\
\text { Paniceae } \\
\text { Aveneae }\end{array}$ & $\begin{array}{r}73.00 \pm 13.23 \\
58.39 \pm 9.58 \\
19.31 \pm 7.86 \\
7.79 \pm 1.77 \\
1.32 \pm 0.36 \\
0.81 \pm 0.22 \\
0.25 \pm 0.15\end{array}$ & $\begin{array}{l}2.232 \pm 0.058 \\
2.738 \pm 0.087 \\
2.804 \pm 0.086 \\
0.967 \pm 0.024 \\
0.062 \pm 0.002 \\
1.763 \pm 0.025 \\
0.187 \pm 0.004 \\
0.081 \pm 0.003\end{array}$ \\
\hline
\end{tabular}

weight, and mean and maximum lateral movement of the diaspore; and culm biomass and height of the parents. Previous results indicated that the sparse species have smaller propagules than the common species, and differences in dispersal inferred from propagule size may be related to colonization and establishment in the prairie (Rabinowitz, 1978a).

NATURAL HISTORY-The seven species of grasses under study (Table 1) were selected to represent a wide range of abundance from common to locally very rare at the Tucker Prairie Research Area, in Callaway County, Missouri. Tucker Prairie is a 64-ha remnant of tall grass or true prairie (Weaver, 1954) on which the sod has never been turned (Kucera, 1956). The site has been burned on an approximately 4-yr rotation since 1956.

The four sparse species, in addition to occurring in low abundance on the study site, are never found as "dominants" in the various habitats where they occur. They are consistently sparse throughout their wide ranges (Hitchcock, 1950). The three common grasses, in contrast, are often cited as tall-grass dominants (Weaver, 1954).

All seven species are perennial, and individuals are capable of repeated flowering over several years. The propagules of all species exhibit innate dormancy, which is gradually lost after release from the parent culm. There are two periods of natural germination in the prairie, the autumn and the spring. The three C3 species (Agrostis hiemalis, Sphenopholis obtusata, and Festuca paradoxa) flower and disperse early (Rabinowitz et al., in press; Rabinowitz and Rapp, in press), and at least some of their propagules have lost the innate dormancy by autumn. These species germinate in both autumn and spring, and the seedlings are capable of overwintering. The $\mathrm{C} 4$ species (Setaria geniculata, Andropogon gerardi, A. scoparius, and Sorghastrum nutans) disperse later in the season and germinate predominantly in the spring. By snowfall, most of the diaspores of the sparse species have fallen from the parent culms, but some culms of the common species may be beaten down by snow prior to release of the diaspores (Rabinowitz and Rapp, in press).

There is little long-term persistence of seed in the soil (Rabinowitz, in press), and the seed bank for these grasses appears transient (Types I and II in the terminology of Thompson and Grime, 1979). The large hygroscopic awns of the common species probably effect redistribution of the propagules once they have reached the soil (Peart, 1979).

Methods AND RESUlts-The propagules used in these experiments were collected during the summer of 1977 and stored in kraft paper bags at room temperature. Fifty diaspores of each species were weighed individually on a Cahn electrobalance (Table 1).

Abundance-Biomass of above-ground live material for each species (Table 1) was determined in 90 randomly placed $0.10 \mathrm{~m}^{2}$ clipped quadrats by methods detailed elsewhere (Rabinowitz 1978a, Rabinowitz, Bassett and Renfro, 1979). We employ biomass $\left(\mathrm{g} / \mathrm{m}^{-2}\right)$ of the species as a measure of abundance, generally to rank order. Abundance here is defined as the number of ramets (physiologically independent individuals) which, for grasses, is roughly equal to the number of full-grown tillers (Ong, 1978; Ong, Marshall and Sagar, 1978). However the species with large biomass $\mathrm{m}^{-2}$ also are large in stature, are coarser vegetatively, and have taller flowering culms. The possibility arises, then, that the species have greater biomass $\mathrm{m}^{-2}$ simply because they are larger rather than because they have a greater number of tillers.

To determine whether we are making this error, we measured culm biomass at the time 
TABLE 2. Dry weight of mature flowering culm (g) and height at dispersal (top of culm, $m$ )

\begin{tabular}{lcc}
\hline \hline & $\begin{array}{c}\text { Weight (g) } \\
\bar{x} \pm \text { s.E. } \\
N=50\end{array}$ & $\begin{array}{c}\text { Heigh (m) } \\
\bar{x} \pm \text { s.E. } \\
N=50\end{array}$ \\
\hline Andropogon scoparius & $1.73 \pm 0.11$ & $0.882 \pm 0.017$ \\
Andropogon gerardi & $4.20 \pm 0.15$ & $1.635 \pm 0.028$ \\
Sorghastrum nutans & $3.37 \pm 0.12$ & $1.378 \pm 0.037$ \\
Festuca paradoxa & $0.466 \pm 0.016$ & $0.720 \pm 0.015$ \\
Agrostis hiemalis & $0.109 \pm 0.007$ & $0.760 \pm 0.022$ \\
Setaria geniculata & $0.518 \pm 0.022$ & $1.030 \pm 0.016$ \\
Sphenopholis obtusata & $0.135 \pm 0.009$ & $0.673 \pm 0.018$ \\
\hline
\end{tabular}

each species is largest by collecting 50 flowering culms of each species. These were clipped at soil level, dried at $80 \mathrm{C}$, and weighed. Means of biomass $\mathrm{m}^{-2}$ (Table 1 ) and culm biomass (g, Table 2) for eight species (including Sporobolus heterolepis) are weakly linearly correlated (both variables $\ln$-transformed, $r=$ $0.82,0.05 \geqslant P \geqslant 0.01$ ). Thus, there are two possibilities: 1) that culm biomass alone accounts for the differences in mean biomass $\mathrm{m}^{-2}$ among the species, or 2) that both large culm biomass and a high number of tillers contribute to a large biomass $\mathrm{m}^{-2}$. If culm biomass alone determines biomass $\mathrm{m}^{-2}$ and species are equally abundant, a double logarithmic plot of biomass $\mathrm{m}^{-2}$ vs. culm biomass will have a slope of unity. If the slope of the line is greater than unity, biomass $\mathrm{m}^{-2}$ increases faster than does culm biomass. As a rough investigation of this idea, we calculated the slope of the first principal axis for mean biomass $\mathrm{m}^{-2} \mathrm{vs}$. mean stature for eight species (Sokal and Rohlf, 1969). The slope of the first principal axis is 3.90 , and the $95 \%$ confidence limits are 1.40 and 8.36 . The lower confidence limit does not overlap with 1.0. Thus, on the level of tillers (but not necessarily genetic individuals), the species with greater biomass $\mathrm{m}^{-2}$, in addition to being larger, are also more numerous. Subsequently, the term abundance refers to the biomass measurements.

Abundance, parent size, and diaspore weight-Abundance and diaspore weight (Table 1) are weakly correlated (Spearman rank correlation coefficient $r_{\mathrm{s}}=0.71, N=8$, $0.05 \geqslant P \geqslant 0.01$; Snedecor and Cochran, 1967). The common species have heavier diaspores than the sparse species. Mean weight of the mature flowering culm (Table 2) and mean diaspore weight are closely related $\left(r_{\mathrm{s}}=\right.$ $0.97, N=8, P \leqslant 0.01$ ). Species of small stature produce small seeds. A least-squares linear regression of mean seed weight on mean stature for seven species (both variables logarith- mically transformed) indicates a slope of 1.00 ( $95 \%$ confidence limits 0.24 to 1.77 ). This value suggests simple allometry of parent and offspring size.

Because species of small stature are sparse, we have the result that sparse species have small diaspores (Rabinowitz, 1978a). Despite the strong relationship between size of parent and size of offspring, there is no relationship of stature to the mean number of spikelets produced on a culm ( $\left.r_{\mathrm{s}}=0.36, N=7\right)$. Thus it is unnecessary to make arguments concerning tradeoffs in offspring size and number (but see Werner and Platt, 1976). A central goal is to explore the consequences for dispersal of the size of diaspores.

Morphology of diaspores-Morphological differences among the diaspores are related to their size (Fig. 1) and are critical to understanding dispersal behavior. Diaspores in the tribe Andropogoneae (Andropogon gerardi, A. scoparius, and Sorghastrum nutans) are large ( 2.2 to $2.8 \mathrm{mg}$ ), heavily ornamented, and morphologically complex. The propagule consists of two spikelets (=units of the inflorescence). One spikelet, which is one-flowered and sessile, contains the caryopsis (=grain) and bears a long twisted awn. The other spikelet, which is pedicellate (=stalked) and usually sterile, either persists ( $A$. scoparius), falls off $(A$. gerardi), or is absent ( $S$. nutans). The diaspore also bears a rachis segment ( $=$ a portion of the inflorescence branch), which is morphologically convergent with the pedicel of the sterile spikelet. These two structures bear long hairs which are crucial to dispersal. Andropogon scoparius is by far the hairiest of the three; $S$. nutans and $A$. gerardi are about equally hairy.

The propagule of Festuca paradoxa is lenticular, intermediate in weight $(1.0 \mathrm{mg})$, and unadorned; it illustrates the basic grass diaspore, the caryopsis with the lemma and palea. The diaspore of Setaria geniculata is approximately hemispherical, heavy $(1.8 \mathrm{mg})$, and carries the small glumes and a sterile lemma (=bracts).

The remaining two species, Sphenopholis obtusata and Agrostis hiemalis, have very small diaspores (0.06 to $0.19 \mathrm{mg}$ ). Sphenopholis obtusata is unusual in having two morphologically distinct types of diaspores, one double the weight of the other. Each spikelet has two florets. When mature, one diaspore falls above the glumes and thus is unornamented, the other falls below the glums and bears them during dispersal. Both diaspores have a flattened shape, the heavier diaspore being quite irregular. The propagule of $A$. hiemalis is flat- 

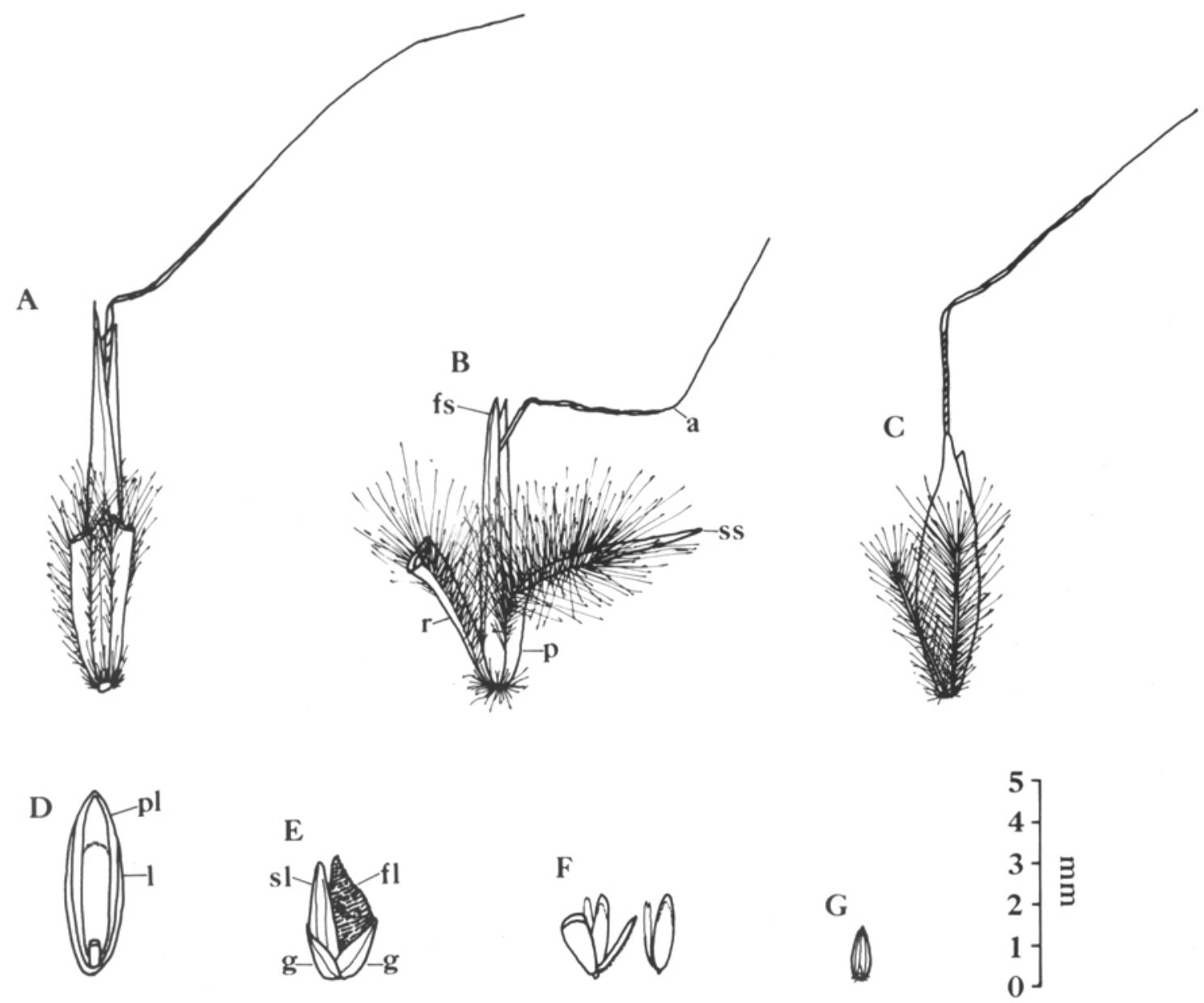

Fig. 1. Diaspores of the prairie grasses: A. Andropogon gerardi, B. A. scoparius, C. Sorghastrum nutans, D. Festuca paradoxa, E. Setaria geniculata, F. Sphenopholis obtusata, diaspore with glumes (left) and without glumes (right), and G. Agrostis hiemalis. Symbols: a, awn; g, glume; r, rachis segment; p, pedicel; fs, fertile spikelet, ss, sterile spikelet; l, lemma; fl, fertile lemma; and pl, palea.

tened and unadorned; it resembles Festuca paradoxa morphologically but is one-twentieth the weight. The seeds are dust-like and difficult to see with the unaided eye, but are viable and readily germinate. In addition to dispersing individual "seeds," A. hiemalis also disperses as a "tumble weed"; the panicles break from the parent and roll in the wind (Rabinowitz and Rapp, 1979).

Terminal velocity-Terminal velocity, which reflects air resistance of a falling diaspore, has been used as a standard descriptor of propagule movement (Sheldon and Burrows, 1973; Burrows, 1973, 1975a, 1975b; Werner and Platt, 1976; Platt and Weis, 1977). Terminal velocities were measured by timing the fall of 30 diaspores of each species through a plastic pipe $9.9 \mathrm{~cm}$ in diameter by $285.6 \mathrm{~cm}$ in length. Possible static electricity was removed by rinsing the pipe with GTC-59. Terminal velocity was calculated from the time elapsed during the diaspore's fall. Seeds reach terminal velocity very quickly (Sheldon and Burrows, 1973), so that the time elapsed during acceleration should be an insignificant source of error.

The mean terminal velocities (Table 3 ), measured by dropping propagules down a pipe, range from 82 to $209 \mathrm{~cm} \mathrm{sec}{ }^{-1}$. Analysis of variance shows that the terminal velocities differ among species $\left(F_{\mathrm{s}}=157\right)$. An a posteriori test (Sokal and Rohlf, 1969) indicates tha. the means fall into four groups at the $5 \%$ level. Three species show low terminal velocities: Agrostis hiemalis, the two forms of Sphenopholis obtusata, and Andropogon scoparius. Andropogon gerardi has intermediate terminal velocity. Three species have high terminal velocities: Sorghastrum nutans and Festuca paradoxa do not differ significantly; Setaria ge- 
TABLE 3. Terminal velocities ( $\vec{x} \pm$ S.E.) of grass diaspores determined by fall rate through a plastic tube $(N=30)^{\mathrm{a}}$

\begin{tabular}{lc}
\hline \multicolumn{1}{c}{ Species } & $\begin{array}{c}\text { Terminal velocity } \\
(\mathrm{cm} / \mathrm{sec})\end{array}$ \\
\hline Setaria geniculata & $209 \pm 8$ \\
Sorghastrum nutans & $194 \pm 4 \S$ \\
Festuca paradoxa & $191 \pm 5 \S$ \\
Andropogon gerardi & $154 \pm 4$ \\
Agrostis hiemalis & $96 \pm 2 \dagger$ \\
Andropogon scoparius & $91 \pm 3 \dagger$ \\
Sphenopholis obtusata & \\
$\quad$ with glumes & $87 \pm 2 \dagger$ \\
without glumes & $82 \pm 2 \dagger$ \\
\hline
\end{tabular}

a $\$, \uparrow$ A group of means not statistically different at the $5 \%$ level by an a posteriori test.

niculata has the highest terminal velocity. The estimates for terminal velocities are similar to those of Platt and Weis (1977) for a variety of prairie dicots but greater than those of Sheldon and Burrows (1973), who studied pappus-bearing Compositae diaspores.

Diaspore movement-Movement of diaspores was measured by dropping propagules in still air from a height of $1 \mathrm{~m}$ onto a table covered with kraft paper. Lateral distance that a diaspore travelled was measured from a mark directly beneath the release point.

While it might seem that measuring dispersal in a constant lateral wind (i.e., with a fan blowing) would be more realistic, consideration shows that it makes no difference to relative movement of the diaspores whether the air is moving or still. Burrows (1973), Sheldon and Burrows (1973), and Burrows (1975b) have shown that the major effect of dispersal structures (the Compositae pappus, for instance) is to lower terminal velocity. With the exception of symmetrically winged seeds with a central concentration of mass (such as the diaspores of the Bignoniaceae), which can achieve a lateral trajectory in still air by a gliding movement (Burrows, 1975b), dispersal structures on propagules act to keep them airborne longer or to orient them, not to impart movement over horizontal distance. "In all winds, excluding those of exceptional strength, the effect of wind in producing a lateral motion whilst the unit is falling is negligible" (Burrows, 1973). Thus the effect of a lateral air current on fall distances of propagules is to attenuate slightly (if at all) or stretch the distribution, not to alter its shape or the rank order among species. The relative dispersal capacities compared among species, therefore, will remain identical whether the air is moving or still. Working in still air is simply more convenient.

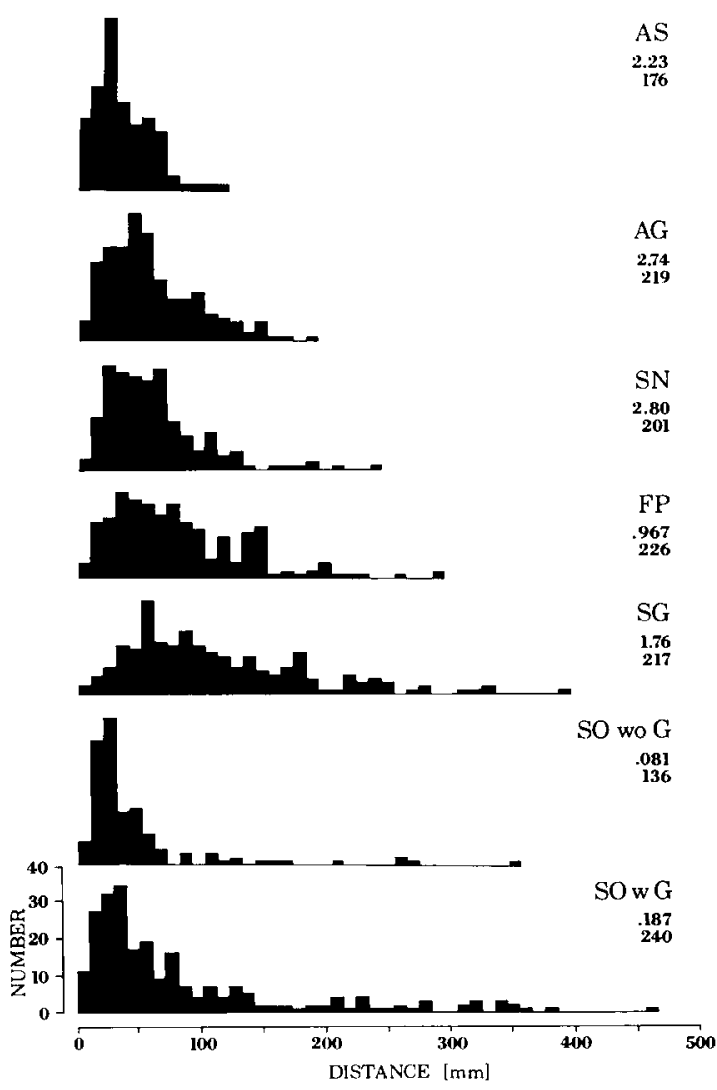

Fig. 2. Distributions of lateral movement $(\mathrm{mm})$ of propagules dropped in still air from the height of $1 \mathrm{~m}$. Species listed in order of abundance, from high to low. AS, Andropogon scoparius; AG, A. gerardi; SN, Sorghastrum nutans; FP, Festuca paradoxa; SG, Setaria geniculata; SO w/o G, Sphenopholis obtusata without glumes; SO w G, S. obtusata with glumes. Beneath the species designation, propagule weight $(\mathrm{mg})$ and sample size are given. The radial symmetry of the fall patterns about the drop point verified that the air was still. The observed movements are not due to small lateral air movements. The propagules do not bounce very much when they hit the table surface; so the distributions observed are due to travel during fall. The exception is the hemispherical propagule of Setaria geniculata, which can bounce an appreciable distance. Agrostis hiemalis is omitted from this portion of the study because the propagules are too small to be found if they are dropped from the height of $1 \mathrm{~m}$.

The distributions of lateral movement of diaspores of the six species ranked in order of abundance from high to low (Fig. 2) are all significantly right-skewed and leptokurtic (Snedecor and Cochran, 1967). When a logarithmic transformation is applied, five of the seven distributions become significantly leftskewed (one remains right-skewed and one is not skewed). Thus, most of the distributions are neither normal nor lognormal. However, 
TABLE 4. Lateral movement $(\mathrm{mm})$ of diaspores dropped from a height of $1 \mathrm{~m}$ in still air. Species listed in order of abundance from high to low

\begin{tabular}{|c|c|c|c|c|c|c|c|c|}
\hline \multirow[b]{2}{*}{ Species } & \multirow[b]{2}{*}{$N$} & \multicolumn{2}{|c|}{ Arithmetic } & \multicolumn{3}{|c|}{ Geometric } & \multirow[b]{2}{*}{ Maximum } & \multirow{2}{*}{$\begin{array}{l}\text { Upper } 5 \% \\
(\bar{x} \pm \text { S.E. })\end{array}$} \\
\hline & & mean & S.E. & mean & -1 S.E. & +1 s.e. & & \\
\hline Andropogon scoparius & 176 & 34.4 & 1.7 & 26.8 & 25.3 & 28.5 & 114 & $88.3 \pm 5.8$ \\
\hline A. gerardi & 219 & 57.0 & 2.4 & 46.2 & 44.1 & 48.4 & 185 & $145.8 \pm 5.6$ \\
\hline Sorghastrum nutans & 201 & 58.3 & 2.7 & 47.7 & 45.5 & 50.0 & 235 & $168.0 \pm 11.1$ \\
\hline Festuca paradoxa & 226 & 78.2 & 3.5 & 61.5 & 58.6 & 64.6 & 285 & $219.1 \pm 11.1$ \\
\hline Setaria geniculata & 217 & 107.9 & 4.7 & 86.6 & 82.5 & 90.8 & 388 & $291.4 \pm 13.4$ \\
\hline \multicolumn{9}{|l|}{ Sphenopholis obtusata } \\
\hline without glumes & 136 & 44.5 & 4.6 & 30.5 & 28.5 & 32.7 & 344 & $235.1 \pm 25.0$ \\
\hline with glumes & 240 & 83.0 & 5.6 & 50.8 & 47.5 & 54.3 & 460 & $342.5 \pm 12.2$ \\
\hline
\end{tabular}

logarithmic transformation corrects for kurtosis in five of seven distributions (two remain leptokurtic). Therefore, both arithmetic and geometric means and standard errors are presented (Table 4).

Maximum lateral distance travelled by the upper $5 \%$ of the propagules (Table 4) is a realistic metric of dispersal capacity because the ability to disperse to distant sites is reflected in the extreme movements of diaspores. How this dispersal ability relates to the success of colonization will depend on numerous factors (for instance, the distribution of safe sites within the landscape) in addition to dispersal to distant sites. Propagules of sparse species travel farther than those of common species (Fig. 2). Maximum lateral movement (upper $5 \%$ of the propagules) is significantly correlated with abundance $\left(r_{\mathrm{s}}=0.94, N=7\right)$. A parametric regression of maximum lateral movement on the logarithm of biomass abundance is significant at the $1 \%$ level $\left(F_{\mathrm{s}}=27.3\right)$.

Release of seeds from natural height-In the field, a propagule's height of release is greater for the more common species than for the sparse (Table 2), and height of release is a factor cited as important in determining how far a seed disperses (Harper, 1977). To assess the effect of dropping the seed from a height of 1 $m$ as opposed to their natural height at dispersal in the field, we selected two species, one with the heaviest seed, Sorghastrum nutans (2.8 $\mathrm{mg}$ ), and one with light seeds, Sphenopholis obtusata (with glumes, $0.19 \mathrm{mg}$ ). Seeds of these species were released from their natural heights ( 1.38 and $0.67 \mathrm{~m}$, respectively), by methods described for the previous experiment.

The variances of the four distributions (each species at two heights of release) are unequal at the $5 \%$ level by an $F$ test, for both untransformed and In-transformed data. Non-parametric comparison of pairs by a Mann-Whitney
$U$ test shows that none of the distributions differs from any other at the 5\% level. For both species, the dispersal distance travelled by all seeds is not changed by changing the height of release. In addition, for distance dispersed by all seeds released, the two species do not differ from each other, regardless of the height from which the seeds were released.

When dropped from the constant height of $1 \mathrm{~m}$, maximal dispersal distance (upper $5 \%$ of the fall distances) of the two species differs (Mann-Whitney $\mathrm{U}, P=0.01$ ). The small seeds of the sparse species disperse farther than large seeds of the common species. When dropped from their natural heights, the dispersal capacities of the two species do not differ $(P=$ 0.16). When the height of release for Sphenopholis obtusata is lowered from 1.0 to 0.67 $\mathrm{m}$, the dispersal capacity lowers, and the upper $5 \%$ of seeds does not travel so far $(P=0.01)$. However, when the height of release for Sorghastrum nutans is raised from 1.0 to $1.38 \mathrm{~m}$, the dispersal capacity does not change $(P=$ 0.31 ). Thus, the dispersal of the sparse species is sensitive to change in height of release, but the dispersal of the common species, whose heavy awned seeds fall straight downward, is not affected by the change in height of release.

Dispersal in the field-In order to investigate whether the differences among species observed in the laboratory also occur in nature, we established a series of sticky seed traps around isolated clumps of each species (Rabinowitz and Rapp, 1979). The traps were modelled after Werner (1975). Twenty petri dishes (9-cm diam.) containing filter paper sprayed with aerosol Tanglefoot were placed near the soil at distances uf $0,0.5,1.0,1.5$, and $2.0 \mathrm{~m}$ from the clump at four compass points. Surrounding vegetation was mowed or clipped to a radius of $4 \mathrm{~m}$ or more to remove other culms. Replicate clumps and years (1978 and 1979) are combined (Table 5). 
TABLE 5. Dispersal curves for seven species of prairie grasses from isolated clumps to sticky traps at 5 distances up to $2.0 \mathrm{~m}$. A shallow slope indicates wide dispersal; a steep slope indicates restricted dispersal. Least squares linear regression of distance $(m)$ against ln-transformed (number of seeds captured +1$)^{\mathrm{a}}$

\begin{tabular}{lccccc}
\hline \hline \multicolumn{1}{c}{ Species } & $\begin{array}{c}\text { Total no. } \\
\text { seeds }\end{array}$ & $\begin{array}{c}\text { Total no. } \\
\text { traps }\end{array}$ & Intercept & Slope & Fs \\
\hline Andropogon scoparius & 66 & 60 & 3.58 & -1.33 & $64.8^{* *}$ \\
Andropogon gerardi & 61 & 60 & 3.60 & -1.58 & $16.0^{*}$ \\
Sorghastrum nutans & 27 & 60 & 2.16 & -0.47 & $1.27 \mathrm{n} . \mathrm{s}$. \\
Festuca paradoxa & 66 & 60 & 3.53 & -1.26 & $143.0^{* *}$ \\
Agrostis hiemalis & 127 & 40 & 3.78 & -1.18 & $2.02 \mathrm{n} . \mathrm{s}$. \\
Setaria geniculata & 36 & 60 & 2.63 & -1.39 & $6.25 \mathrm{n} . \mathrm{s}$. \\
Sphenopholis obtusata & 287 & 20 & 4.57 & -0.61 & $16.5^{* *}$ \\
\hline
\end{tabular}

a $*, 0.05 \geqslant P>0.01 ; * *, P \leqslant 0.01 ;$ n.s., $P>0.05$

When the logarithm of the number of seeds captured is plotted against distance, the slope of the regression line reflects the extent of dispersal. If the slope is shallow, dispersal is wide; if the slope is steep, dispersal is limited. The slopes of the seven grasses range from -0.47 to -1.58 . Four of the seven regressions are significant at the 5\% level. There is no clear relationship of the slopes of the dispersal curves with abundance or with any of the other traits.

Summary of character correlations-The relationships among biomass abundance, stature, height at dispersal (the parental characteristics), propagule weight, terminal velocity, mean fall distance, maximum fall distance (dispersal characteristics), and the slope of the field dispersal curve are summarized in a nonparametric correlation matrix (Table 6). Caution must be exercised in the interpretation of these correlations because multiple assessments of statistical significance are performed. Conservatively, there are two significant correlation coefficients (out of 28) at the $1 \%$ level. First, sparse species have greater maximum lateral movement than do common species. Secondly, species of small stature have smaller diaspores than do species of large stature. Oth- er correlations are much weaker than these two, and notably, there is no correlation of maximum fall distance with stature nor of slope with height. Dispersal capacity, then, is more closely correlated with abundance than to propagule characteristics.

Discussion-Dispersal ability of six species of prairie grasses (the lateral movement of the upper $5 \%$ of the diaspores) is strongly correlated with biomass abundance. In the laboratory, sparse species have greater dispersal abilities than common species. It is notable that dispersal ability is more closely correlated with a population level parental attribute (abundance) than with a more proximal propagule characteristic (weight) or with other dispersal metrics (terminal velocity). The absence of two correlations is conspicuous: there is no relationship between the stature of a species and the number of spikelets it produces (no "conservation" of total reproductive material), and there is no relationship between the slope of the dispersal curve in the field and the height of release of the diaspores.

Simple allometry appears to dictate diaspore weight. For these seven grasses, species which are small in stature have small seeds, and species with large stature, large seeds. This

TABLE 6. Matrix of non-parametric correlation coefficients (Spearman $r_{s}$ ) for parental, diaspore, and dispersal characteristics $^{\mathrm{a}}$

\begin{tabular}{lccccrrr}
\hline \hline & $\begin{array}{c}\text { Stature of } \\
\text { parent }\end{array}$ & $\begin{array}{c}\text { Height at } \\
\text { dispersal }\end{array}$ & $\begin{array}{c}\text { Propagule } \\
\text { weight }\end{array}$ & $\begin{array}{c}\text { Terminal } \\
\text { velocity }\end{array}$ & $\begin{array}{c}\text { Mean fall } \\
\text { distance }\end{array}$ & $\begin{array}{c}\text { Maximum fall } \\
\text { distance }\end{array}$ & $\begin{array}{c}\text { Slope of } \\
\text { dispersal curve }\end{array}$ \\
\hline Abundance & 0.71 & 0.57 & 0.71 & 0.30 & 0.42 & $-0.94^{*}$ & -0.32 \\
Stature of parent & & 0.86 & $0.97^{*}$ & 0.49 & 0.20 & 0.67 & 0.39 \\
Height of dispersal & & & 0.80 & 0.68 & -0.01 & 0.40 & 0.43 \\
Propagule weight & & & & 0.54 & 0.11 & 0.68 & 0.18 \\
Terminal velocity & & & & & -0.64 & -0.16 & -0.18 \\
Mean fall distance & & & & & & 0.46 & -0.20 \\
Maximum fall distance & & & & & & & -0.54 \\
\hline
\end{tabular}

\footnotetext{
a $*$ Indicates $P \leqslant 0.01$.
} 
seemingly straightforward scaling effect (elephants have larger offsping than mice) forms the null hypothesis (Strong, 1980) for explaining species to species variation in seed size among related taxa. Kaplan and Salthe (1979) have recently renewed Pilbeam and Gould's (1974) caution that scaling of body size is a "criterion of subtraction" which must be taken into account before more elaborate alternative hypotheses for the evolution of life history traits are entertained and explored (see also Wassersug et al., 1979). This crucial first step has been unfortunately bypassed in discussions on the evolution of propagule size and life histories in plants (Werner, 1976, 1979; Werner and Platt, 1976; Wilbur, 1976, 1977; Platt and Weis, 1977), and thus the conclusions of these studies lack the force they might otherwise have.

It initially seems paradoxical that small unornamented diaspores (e.g., the two forms of Sphenopholis obtusata) show greater dispersal capacity than elaborately ornamented propagules (e.g., Andropogon scoparius) which seem endowed with dispersal structures. These propagules (A. scoparius and the three smallest propagules, Agrostis hiemalis and the two forms of $S$. obtusata) have similar low terminal velocities, the former by being ornamented, the latter simply by being small. The dispersal differences are explained by differences in fall behavior due to morphology. The small propagules are flattened and somewhat irregularly shaped. They tumble and glide during fall and thus achieve lateral movement. They probably behave in the manner of the plain winged seeds described by Burrows (1975b). During the fall of Andropogon scoparius, the hairs function both as a drag parachute (slowing fall) and a guide parachute (orienting the embryo lowermost). Thus, these slowly falling propagules move more or less straight downward, with very little lateral movement. In $A$. gerardi and Sorghastrum nutans, with higher terminal velocities, the "dispersal" structures probably have more of a guide than a drag action. These species have greater fall distances than $A$. scoparius. The unadorned propagules of intermediate weight (Festuca paradoxa and Setaria geniculata) fall intermediate distances. Thus, weight, morphology, and terminal velocity together determine the dispersal patterns of a diaspore, and none alone is sufficient to account for the dynamics of movement.

The movement patterns of these propagules illustrate that terminal velocity alone is a deceptive metric of dispersal. Species with similar terminal velocities can have very different fall movements due to morphological factors. Peart (1979) gives an excellent account of the influence of morphology on diaspore movement once the ground is reached.

In these experiments, the propagules were released from a constant height $(1 \mathrm{~m})$, but in nature, the height of release varies among the species. As the season progresses, the height of the vegetation in the prairie steadily increases, and dispersing species generally bear their inflorescences just above the level of the grass. Because the common species flower later in the season, their culms are taller and their seeds released from greater heights (Table 2). When propagules of two selected species were released at natural height in the laboratory, differences in maximum fall distance observed at constant height disappeared.

Height of release is cited as an important factor in the distance travelled by diaspores (Sheldon and Burrows, 1973; Harper, 1977), but this effect does not appear in our data. It is quite surprising that so large a range in height of release $(0.7$ to $1.6 \mathrm{~m})$ is not reflected in the dispersal patterns. When dispersal was observed in nature, the slopes of the dispersal curves, which measure the extent of propagule movements, were not related to height of release, to abundance, or to any of the other traits (Table 6). In our experiments, the surrounding vegetation was clipped to increase the likelihood of seed capture. Under usual conditions, the vegetation is also taller when the culms are taller, and the downward distance a propagule travels before it encounters objects which halt flight is not appreciably greater for the taller species. In this case, the dispersal differences among the species will be even smaller. Other explanations for loss of discrimination among the species include catapulting of seeds (from culms waving in the wind), general environmental variability, and lack of precision in the field methods. The precise differences in dispersal behavior between species observed in the laboratory are obscured in nature. However, the laboratory data reveal differences among sparse and common species which reflect potential dispersal ability. These differences result from intrinsic propagule behaviors, and by inference, morphological adaptation of the diaspore to dispersal.

\section{LITERATURE CITED}

BAKKER, D. 1960. A comparative life-history study of Circium arvense (L.) Scop. and Tussilago farfara L. the most troublesome weeds in the newly reclaimed polders of the former Zuiderzee, p. 205-222. In J. L. Harper [ed.], Symp. Br. Ecol. Soc. 1. 
Burrows, F. M. 1973. Calculation of the primary trajectories of plumed seeds in steady winds with variable convection. New Phytol. 72: 647-664.

- 1975a. Calculation of the primary trajectories of dust seeds, spores and pollen in unsteady winds. New Phytol. 75: 389-403.

L. 1975b. Wind-borne seed and fruit movement. New Phytol. 75: 405-418.

Friedman, J., AND Z. Stein. 1980. The influence of seed-dispersal mechanisms on the dispersion of $A n$ astatica hierochuntica (Cruciferae) in the Negev Desert, Israel. J. Ecol. 68: 43-50.

GrigGS, R. F. 1940. The ecology of rare plants. Bull. Torrey Bot. Club 67: 565-594.

Guppy, H. B. 1906. Observations of a naturalist in the Pacific. II. Plant-dispersal. Macmillan, London.

- . 1917. Plants, seeds and currents in the West Indies and Azores. Macmillan, London.

HARPer, J. L. 1977. Population biology of plants. Academic Press, London.

Hitchсock, A. S. 1950. Manual of the grasses of the United States. Second edition. U.S.D.A. Misc. Pub. 200.

Kaplan, R. H., and S. N. Salthe. 1979. The allometry of reproduction: an empirical view in salamanders. Amer. Nat. 113: 671-689.

KuCERA, C. L. 1956. Grazing effects on composition of virgin prairie in north-central Missouri. Ecology 37: 389-391.

- 1961. The grasses of Missouri. U. of Missouri Press, Columbia.

ONG, C. K. 1978. The physiology of tiller death in grasses. I. The influence of tiller age, size, and position. $J$. Brit. Grassland Soc. 33: 197-204.

—, C. Marshall, and G. R. Sagar. 1978. The physiology of tiller death in grasses. II. Causes of tiller death in a grass sward. J. Brit. Grassland Soc. 33: 205-211.

Peart, M. H. 1979. Experiments on the biological significance of the morphology of seed-dispersal units in grasses. J. Ecol. 67: 843-863.

PIJL, VAN Der L. 1972. Principles of dispersal in higher plants. Second edition. Springer-Verlag, New York.

Pilbeam, D., And S. J. Gould, 1974. Size and scaling in human evolution. Science 186: 892-901.

PlatT, W. J., AND I. M. Weis. 1977. Resource partitioning and competition within a guild of fugitive prairie plants. Amer. Nat. 111: 479-513.

Poole, A. L., And D. Cairns. 1940. Botanical aspects of ragwort (Senecio jacobaea L.) control. Bull. N.Z. Dept. Sci. Industr. Res. 82: 1-66.

Rabinowitz, D. 1978a. Abundance and diaspore weight in rare and common prairie grasses. Oecologia 37: 213-219.

- $1978 \mathrm{~b}$. Dispersal properties of mangrove propagules. Biotropica 10: 47-57.

- 1978c. Early growth of mangrove seedlings in Panama and an hypothesis concerning the relationship of dispersal and zonation. J. Biogeogr. 5: 113-133.

_. In press. Buried viable seeds in a North American tall-grass prairie: the resemblance of their abundance and composition to dispersing seeds. Oikos.

- , B. K. Bassett, and G. E. Renfro. 1979. Abundance and neighbourhood structure for sparse and common grasses in a Missouri prairie. Amer. J. Bot. 66: $867-869$

- - AND J. K. RAPP. 1979. Dual dispersal modes in Hairgrass, Agrostis hiemalis (Walt.) B.S.P. (Gramineae). Bull. Torrey Bot. Club 106: 32-36. $\longrightarrow$, AND $\longrightarrow$. In press. Seed rain in a North American tall-grass prairie. J. Appl. Ecol.

$\longrightarrow,-$, V. L. Sork, B. J. RATHCKe, G. A. ReEse, AND J. C. WEAVER. In press. Phenological properties of wind- and insect-pollinated prairie plants. Ecology.

RidLEY, H. N. 1930. The dispersal of plants throughout the world. Reeve, Ashford.

SAlisbury, E. J. 1942. The reproductive capacity of plants. Bell, London.

- 1961. Weeds and aliens. Collins, London.

Sheldon, J. C., ANd F. M. Burrows. 1973. The dispersal effectiveness of the achene-pappus units of selected Compositae in steady winds with convection. New Phytol. 72: 665-675.

SNedecor, G. W., AND W. G. Cochran. 1967. Statistical methods. Sixth edition. Iowa State University Press, Ames, Iowa.

Sokal, R. R., AND F. J. RohlF. 1969. Biometry: the principles and practice of statistics in biological research. W. H. Freeman, San Francisco.

Strong, D. R., JR. 1980. Null hypotheses in ecology. Synthese 43: 271-285.

Thompson, K., and J. P. Grime. 1979. Seasonal variation in the seed banks of herbaceous species in ten contrasting habitats. J. Ecol. 67: 893-921.

WAssersug, R. J., H. YANG, J. J. SEPKOSKI, JR., AND D. M. RAup. 1979. The evolution of body size on islands: a computer simulation. Amer. Nat. 114: 287295.

WEAVER, J. E. 1954. North American prairie. Johnson, Lincoln, Neb.

WERNER, P. A. 1975. A seed trap for determining patterns of seed deposition in terrestrial plants. Can. J. Bot. 53: 810-813.

- 1976. Ecology of plant populations in successional environments. Systematic Bot. 1: 246-268.

- 1979. Competition and coexistence of similar species. In O. T. Solbrig, S. Jain, G. B. Johnson, and P. H. Raven [eds.], Topics in plant population biology, p. 287-310. Columbia University Press, New York. , and W. J. Platt. 1976. Ecological relationships of co-occurring goldenrods (Solidago: Compositae). Amer. Nat. 110: 959-971.

Wilbur, H. M. 1976. Life history evolution of seven milkweeds of the genus Asclepias. J. Ecol. 64: 223240.

-1977. Propagule size, number, and dispersion pattern in Ambystoma and Asclepias. Amer. Nat. 111: 43-68.

Note added in proof: In addition to considerations of diaspore movements, there is another critical reason for performing the dispersal experiments in still air. If seed movements were measured in horizontally moving air, produced by a fan, for instance, a laminar lateral air flow would result. Although this sort of wind occurs in meters above the surface of vegetation, air movements in the immediate vicinity of dispersing propagules will likely be of other sorts (Tauber, H. 1967. Differential pollen dispersion and filtration. In E. J. Cushing and H. E. Wright,

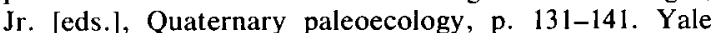
University Press, New Haven.): convection, due to heating and cooling; turbulence, produced by surface roughness; and dead air, beneath the canopy on days of low wind. Dispersing propagules in the wild will commonly experience laminar lateral air flow. Turbulence and convection are difficult to simulate in the laboratory. Thus, doing dispersal experiments in still air is the most realistic case. 